\title{
Economics Journal
}

Novikov, S. /Vol. 2 Num. 2: 4 - 10/ January - June 2020

ISSN Version Web On line: 2711-2454 - DOI: http://dx.doi.org/issn.2711-2454/2020.2.1 http://www.economicsjournal.info/index.php/edu/index

Received: October 15, 2019 - Accepted: november 20, 2019

\section{Optimization of labor processes in innovation enterprises of Russia}

\section{Оптимизация трудовых процессов на инновационных предприятиях России}

\section{Sergey V. Novikov ${ }^{1}$ \\ https://orcid.org/0000-0001-6921-1760}

elibrary.ru: https://elibrary.ru/author_profile.asp?id=807011 https://www.scopus.com/authid/detail.uri?authorId=57192318711

\begin{abstract}
The article shows the need to optimize management decisions to improve the efficiency of labor organization in innovative enterprises. The main tasks of the scientific organization of labor (SOL) for existing and innovative processes are presented. The use of methods of research operations and modeling to optimize labor processes is considered.
\end{abstract}

Keywords: engineering, high-tech production, mathematical methods of operations research, modeling, optimization, scientific organization of labor.

\section{Аннотация}

В статье показана необходимость оптимизации управленческих решений для повышения эффективности организации труда на инновационных предприятиях. Представлены основные задачи научной организации труда как для существующих, так и для инновационных процессов. Рассмотрено использование методов исследования операций и моделирования для оптимизации трудовых процессов.

Ключевые слова: высокотехнологичное производство, математические методы исследования операций, моделирование, оптимизация, машиностроение, научная организация труда.

\section{Introduction}

The aviation industry is one of the high-tech sectors of the country's economy, ensuring the development and production of military and civil products, the level of which largely determines Russia's economic, technological, information security and defense

${ }^{1} \mathrm{PhD}$ in Economics, Associate Professor, Head of Institute of Engineering Economics and Humanities, Moscow Aviation Institute (National Research University), Moscow, Russia. 
capability. A lot of industries, for example, electronic and radio industries act as suppliers to ensure the smooth operation of the aviation industry. Aviation technologies are the catalyst and the engine of the country's scientific and technological progress and the basis for the sustainable development of other industries. The aviation industry market is one of the most capacious and fast-growing, and has a great potential for further development.

The aviation industry of Russia is characterized by the need to introduce external regulation. This regulation should be focused on reducing adverse factors and enhancing the beneficial effects of aeronautical engineering on the development of the country, which is very significant. One of the important tools for managing an aircraft manufacturing enterprise is the planning apparatus for the effective development of enterprises and increasing the productivity of workers (Kanashchenkov, Matveev, Minaev \& Novikov, 2017).

The results of investigations of the Russian Academy of Sciences on the study of the behavior of Russian enterprises show that low labor productivity in high-tech aviation enterprises is connected with management inefficiency. Reducing the possibility of obtaining income by the enterprise did not lead to the strengthening of internal control systems, did not take into account the factors of productivity, competitiveness, resource saving, improved planning, effective organization and optimization of production processes (Pinkovetskaya, 2015; Novikov, 2018).

\section{Methodology and labor organization solutions}

During the research conducted by Professor Rodionova N.V. it was found that "Russian enterprises have shown poor quality management. Thus, according to economists, in the domestic economy, no more than $25 \%$ of all disposable resources are actually mastered, including: human $-15 \%$, financial -10 , intellectual -3.3 . With the same material reserves possessed by Russia, other countries receive $2-3$ times higher volumes of GDP, 3-4 times foreign currency earnings and 4-5 times tax revenues. Russia produces 0.63 units of GDP per unit of total energy costs, while the United States produces 2.9 units, which is 4.6 times more". Labor productivity in Russia is 3-4 times lower than in developed countries. For aviation enterprises, this discrepancy is even more significant, as according to the data in 2017, the output per employee of the aircraft industry was an order of magnitude lower than in the major world aviation centers. According to the state program for the development of the aviation industry for 2013-2025 (Mitrofanova, Demjanchenko, Novikov, Rudakova \& Shmanev, 2017), it is planned to increase the productivity of industrial aircraft building organizations to 19,184 thousand rubles per person per year by 2025, that is, more than 10 times. According to the adopted program, by 2025, reducing the cost of the supplied aircraft based on increasing labor productivity will amount to 3.2 and 10.9 percent of the global market share in terms of money in civil and military aircraft manufacturing, respectively.

Increasing labor productivity growth rates, in the context of the introduction of new high-performance equipment and advanced high-tech at enterprises, is unthinkable without continuous improvement and optimization of work organization solutions. The main task of the organization of labor is to minimize the labor process in time and space while obtaining high production results, quality and competitiveness of finished products and preserving the working capacity of workers. Achieving this goal is only possible on a scientific basis. SOL implies the systematic introduction of scientific research and 


\section{Economics Journal-}

advanced experience into high-tech aviation production (Novikov, 2018). SOL allows the best way to combine technology and people in a single production process, ensures efficient use of material and labor resources, continuous increase in labor productivity contributes to the preservation of human health. All this concerns both existing and innovative processes, which, as a rule, initiate changes in the content of labor, improvement of its organization forms, which are predetermined by the nature of technological processes used at aviation enterprises (Mindlin, Novikov, Kireev, Adamenk \& Belitskaya, 2016; Novikov, 2018).

Without compliance with the level of work organization and the development of technology and production technology, the most advanced innovative solutions will not give the desired result. Otherwise, there are disparities in the level and quality of organizational decisions, which leads to a significant reduction in productivity growth.

In the conditions of increasing the technical equipment of labor, automated production, human functions in high-tech production change: from executive to regulatory duties. The functions of controlling the progress of the productive process, setting up and caring for the equipment, selecting and programming the optimal mode of its operation become predominant. In this case, the introduction of such forms of work organization, which allow the most efficient use of equipment, materials and achieve high productivity of labor with the least expenditure of nervous and muscular energy is of particular importance. To achieve an economical effect, it is necessary to fully take into account the peculiarities of aviation production, which is characterized by the use of advanced technologies and the realization of the full potential of domestic producers of high-tech goods (Novosadov, Burtseva, Repetskaia \& Novikov, 2017; Kraev, Tikhonov \& Novikov, 2018).

The solution of tasks in the field of labor organization depends on the equipment and technology used, the nature of the product, the type of production. At the enterprises of the aviation industry, for example, the continuity of technological processes, large dimensions and power of the operated units determine the use of collective forms of work organization. The main products are manufactured at the technological equipment with numerical program control and flexible automated production facilities. Volumes of production of high-tech aircraft engineering products are in a wide range - from single samples to mass production (Novikov \& Dmitriev, 2018).

To ensure the continuity of technological processes, it is necessary to coordinate carefully in space and time, not only the work of the production team, but also the labor functions of workers employed in servicing, transport shops and other services of preproduction and production logistics. With an uneven production process, when the need for maintenance arises at random moments, and machine downtime is inevitable while waiting for service or workers waiting for service requirements, the task of organizing service for a high-tech aircraft manufacturing process is quite complex. Proper scheduling of work methods, service route minimizes equipment downtime and efficiently uses work time (Pinkovetskaia, Lyubovtseva, Arbeláez-Campillo \& Rojas-Bahamón, 2020).

In engineering, the specifics of organizing the production of high-tech products are determined by the variety of equipment used and technological processes, the type of production, the nomenclature, and the complexity of the product. Produced products include a wide range of different complexity of machines and parts. At machine-building 


\section{Economics \\ Journal}

enterprises with a high level of automation, a wide distribution of multi-station service and the combination of professions of a production and conveyor line have become widespread (Pinkovetskaia, ArbeláezCampillo, Rojas-Bahamón, Gromova, \& Nikitina, 2019).

A very complex system of services for the main production is characteristic of the organization of labor at a high-tech enterprise (Nedelkin, Novikov, Titov, Mikhailova \& Popova, 2017).

Large reserves of accelerating the growth of labor productivity lie in improving the use of equipment, production space, eliminating the loss of working time, which is largely determined by the level of optimization of organizational decisions on labor.

Ensuring coordinated work and effective interaction of people and technology in modern conditions requires new methods based on careful quantitative and qualitative expert analysis of labor and business processes.

Designing the optimal organization of labor should be based on the qualitative and quantitative assessment of its various options, and boil down to choosing the optimal one, which cannot be done without building a mathematical model of the labor process and using the methods of applied mathematics. Areas of application of expert methods in making organizational decisions are used for the analysis and subsequent adoption of management decisions in the following cases: if objects either completely or partially are not amenable to subject description; in the absence of sufficiently reliable statistics on the characteristics of the object; in conditions of high uncertainty of the environment of the object; in case of lack of time and funds to collect information and making decisions in extreme situations. In case of the application of expert methods, it is possible to bring the qualitative assessment of experts to a quantitative form. Thus, for most organizational decisions, we can recommend quantitative analysis and the use of mathematical modeling.

Modern high-tech industrial enterprises are complex systems whose functioning depends on the high-quality organizational management of them. Choosing this or that organizational decision, it is necessary to take into account various contradictory factors and disturbing influences acting on the enterprise (Fedotova, Tikhonov \& Novikov, 2018).

In solving a wide range of problems of optimal control, scientific methods of organizational management are used - operations research, i.e. the choice of optimal (according to a particular criterion) options for organizing and managing targeted processes (operations) based on the construction for its analysis of the mathematical apparatus.

Solving specific tasks of production organization, the use of methods of operations research suggests:

- building economic and mathematical models that are adequate to the object under study for the tasks of making organizational decisions in difficult situations or in conditions of uncertainty; 


\section{Economics Journal}

- study of interrelations that determine the consequences of making decisions, and the establishment of performance criteria, allowing to evaluate the advantage of a variant of action.

The mathematical model of the labor process stands for a system of its characteristics, their interrelations, limitations in mathematical expressions.

Solution to the problem, which provides the optimal, i.e. the maximum (or minimum depending on the content of the task) value of the efficiency criterion and compliance with the limitation is called optimal, it shows which set of organizational measures must be implemented in practice so that the work process becomes the most effective (in terms of the chosen criterion).

The model may also additionally take into account qualitative factors. A comprehensive qualitative and quantitative analysis of an organizational task that precedes the construction of a mathematical model is an integral part of the methodology of operations research. This analysis is carried out in accordance with the principles of the systems approach and involves the identification of all significant relationships between the influencing factors of the subsystems.

The main difference between the organization of labor using mathematical methods from designing the organization of labor in the traditional way is that a model of the labor process is developed, which allows quantitative substantiation of various options for organizing labor and choosing the best one by experimenting abstractly without conducting experiments on high - tech production.

Models of work processes can be very complex mathematical expressions. However, they are based on a relatively simple design. All of them have the form of an equation in which the performance criterion $(\boldsymbol{Z})$ is a function $\boldsymbol{f}$ of the set of variates $\left(\boldsymbol{x}_{\boldsymbol{i}}\right)$ determining the content of the labor process.

$$
Z=f\left(x_{1}, x_{2}, x_{3}, \ldots, x_{i}, \ldots, x_{n}\right)
$$

The equation is called performance function or objective function. It expresses the dependence of the efficiency criterion on the essential variates describing the real labor process.

Prospects for the implementation of the model add to the performance function a number of expressions, equations and inequalities representing the constraints that are imposed on the possible values of the variables, determined by the production capabilities and the resources used.

A specific set of variable values that satisfies these additional conditions is called the solution to the problem. Different sets of variables form a set of solutions. Each of the solutions corresponds to a set of organizational measures, the content of which depends on the nature of the variables being changed.

Working at a mathematical model, attention is focused on formal relations, but this formalism makes it possible to display the content of the real labor process, transferred to the formal scheme of the model. The visibility and adequacy of the model to the process 


\section{- Economics \\ Journal=}

being studied, the ability to focus on the formally presented properties of the labor process allows clarifying the identified structure of the process and determining the direction of research to further refine the model in order to take into account the essential relationships that exist in reality more completely. This shows the active role of mathematical models: with their help, you can once again check that everything important is taken into account and discard irrelevant details.

Evaluation of the relevance of preserving and prospective development of high-tech aviation enterprises, as well as researching the experience of making managerial organizational decisions on labor showed that the cause of the constant internal reorganization of the object and subject of management is the inefficient use of resources of the knowledge-intensive organization (Sozinova, Novikov, Kosnikov, Nemchenko \& Alenina, 2016). The organization systems of production applied at Russian enterprises turned out to be insufficient in the conditions of a rapid technological change.

Existing management decision-making systems most often inadequately reacted to events that are partly predictable, but are developing rapidly in relation to high-tech markets (Novikov \& Veas Iniesta, 2018).

High-tech, knowledge-intensive industrial aviation enterprises often find themselves unprepared for this situation both from the point of view of resources and from the point of view of the lag of time to make the necessary decisions. It is required to improve the existing management systems by identifying, planning and optimizing the adoption of organizational decisions on labor.

\section{Conclusion}

Thus, in this paper, the following statements and results are new:

- necessity of a significant increase in growth rates of labor productivity for a high-tech aircraft engineering enterprise is shown;

- it is revealed that the increase in labor productivity growth rates, in the context of the introduction of new high-performance equipment and advanced high-tech at enterprises, is unthinkable without continuous improvement and optimization of labor organization solutions;

- It is shown that in solving a wide range of problems of optimal control, scientific methods of organizational management - investigation of operations, i.e. the choice of optimal (according to a particular criterion) options for organizing and managing targeted processes (operations) based on the construction for its analysis of the mathematical apparatus.

\section{References}

Fedotova, M. A., Tikhonov, A. I., \& Novikov, S. V. (2018). Estimating the Effectiveness of Personnel Management at Aviation Enterprises. Russian Engineering Research, 38(6), 466-468.

Kanashchenkov, A. I., Matveev, A. M., Minaev, E. S., \& Novikov, S. V. (2017). New Generation Compact Integrated Radar Systems for Aerial Vehicles. Russian Aeronautics, 60(4), 647-652. 


\section{Economics Journal}

Kraev, V. M., Tikhonov, A. I., \& Novikov, S. V. (2018). Economic Conversion in the Aviation Industry. Russian Engineering Research, 38(4), 330-333.

Mindlin, Y. B., Novikov, S. V., Kireev, S. V., Adamenk, A. A., \& Belitskaya, O. V. (2016). Innovative territorial clusters. International Journal of Economics and Financial Issues, 6(8), 251-256.

Mitrofanova, S. V., Demjanchenko, N. V., Novikov, S. V., Rudakova, O. V., \& Shmanev, S. V. (2017). The role and characteristics of the enterprises' working conditions before and after the transition to market relations: A view from macroeconomic perspective. International Journal of Applied Business and Economic Research, 15(13), 63-72.

Nedelkin, A. A., Novikov, S. V., Titov, V. A., Mikhailova, A. V., \& Popova, L. N. (2017). Development of human resources of agro-industrial complex. Journal of Applied Economic Sciences, 12(7), 1932-1942.

Novikov, S. V. (2018). Russian Support for Innovation and Export Growth. Russian Engineering Research, 38(4), 305-308.

Novikov, S. V. (2018). Strategic Analysis of the Development of High-Technology Manufacturing Facilities. Russian Engineering Research, 38(3), 198-200.

Novikov, S. V. (2018). The features of innovative processes in the Russian Federation: Analysis of current practices. Espacios, 39(39), 10.

Novikov, S. V., \& Dmitriev, O. N. (2018). Vision of Genesis of Presentation of Hi-Tech Project during Competitive Selection. Russian Engineering Research, 38(4), 320-322.

Novikov, S. V., \& Veas Iniesta, D. S. (2018). State regulation of the development of the connectivity of the Russian territory]. Espacios, 39(45), 8.

Novosadov, S. A., Burtseva, T. A., Repetskaia, N. V., \& Novikov, S. V. (2017). The formation prospects of the command culture of the organization management thinking in the new paradigm of social and economic development of the society. Journal of Applied Economic Sciences, 12(7), 1996-2002.

Pinkovetskaia, I., Arbeláez Campillo, D. F., Rojas-Bahamón, M. J., Gromova, T., \& Nikitina, I. (2019). Female entrepreneurship development in the Russian Federation. Amazonia Investiga, 8(18), 111-118.

Pinkovetskaia, I., Lyubovtseva, E., Arbeláez Campillo, D., \& Rojas Bahamón, M. (2020). Small and medium enterprises in Russia and other countries. Amazonia Investiga, 9(25), 99-106.

Pinkovetskaya, I. (2015). Modeling indicators of small and medium-sized businesses in the regions using the density function of the normal distribution. Problems of territorial development, 6(80), 93-107.

Sozinova, A. A., Novikov, S.V., Kosnikov, S. N., Nemchenko, G. I., \& Alenina, E. E. (2016). Peculiarities of isolated clusters operation. International Journal of Economics and Financial Issues, 6(8), 19-23. 